\title{
Anti-asthma Drugs Formoterol and Budesonide (Symbicort) Induce Orofacial Clefts, Gastroschisis and Heart Septum Defects in an In Vivo Model
}

\author{
MIROSLAV PETERKA ${ }^{1,2}$, LUCIE HUBICKOVA HERINGOVA ${ }^{3}$, ANDREJ SUKOP $^{1}$ and RENATA PETERKOVA ${ }^{3}$ \\ ${ }^{1}$ Cleft Centre, Clinic of Plastic Surgery, Kralovske Vinohrady University Hospital and Third Faculty of Medicine, \\ Charles University, Prague, Czech Republic; \\ ${ }^{2}$ Institute of Anatomy, First Faculty of Medicine, Charles University, Prague, Czech Republic; \\ ${ }^{3}$ Institute of Histology and Embryology, Third Faculty of Medicine, Charles University, Prague, Czech Republic
}

\begin{abstract}
Background: We had a case in which three consecutive pregnancies resulted in birth of three children with an orofacial cleft. Their mother suffered from bronchial asthma and was treated using symbicort (corticosteroid budesonide plus bronchodilator formoterol) during her pregnancies. A hypothesis was assessed: these antiasthmatics can induce an orofacial cleft in experimental model. Materials and Methods: A single administration of one of five increasing doses (including therapeutically used ones) of Symbicort, budesonide or formoterol was injected into the amnion of a chick embryo on day 4 or 5 of incubation. The teratogenic/lethal effects of the antiasthmatics were assessed on a total of 600 embryos. Results: For budesonide, the teratogenic/lethal effect started at a dose $0.003 \mu \mathrm{g}$ per embryo, for formoterol at $0.3 \mu \mathrm{g}$ and for Symbicort $0.03 \mu \mathrm{g}$. Orofacial clefts and gastroschisis after exposure were found for all three anti-asthmatics. Heart septum defects occurred after exposure to formoterol. Conclusion: The present results support those clinical/epidemiological studies pointing out that antiasthmatics have the potential to induce orofacial clefts, gastroschisis and heart malformations during prenatal development in human.
\end{abstract}

Bronchial asthma affects between 7 to $16 \%$ of pregnant women and its prevalence exhibits an increasing trend (1-3).

This article is freely accessible online.

Correspondence to: Miroslav Peterka, Institute of Anatomy, First Faculty of Medicine, Charles University Prague, U Nemocnice 1563/3, 12800 Prague 2, Czech Republic. E-mail: peterkamm@seznam.cz

Key Words: Teratology, drug safety, reproduction, embryogenesis, development.
Maternal asthma during pregnancy is generally considered a significant risk factor for poor pregnancy outcome (4).

Chronic poorly controlled asthma during pregnancy leads to maternal hypoxemia, which directly or indirectly reduces the supply of the fetus with oxygen $(5,6)$. Therefore, untreated asthma increases the risk of congenital malformations, low birth weight, preterm birth and perinatal mortality $(1,7-11)$.

Asthma medication mainly includes inhaled corticosteroids and bronchodilators $(3,6,12-16)$. The administration of corticosteroids during pregnancy has been associated with congenital malformations in children in some epidemiological studies (1, 17-19), while no association has been reported by others $(9,10,20-25)$. Epidemiological studies have also suggested bronchodilators as potential inducers of major congenital malformations such as cleft lip, cleft palate and gastroschisis in children (25-28). In contrast, Murphy et al. did not find an association between taking inhaled corticosteroids or bronchodilators and an increased risk of congenital malformations (9). Eltonsy et al. performed a detailed systematic review of pregnancy outcomes after administration of bronchodilators ( $\beta 2$ agonists) during pregnancy and pointed out methodological limitations that influence information value and interpretation of such epidemiological studies (28).

Available clinical/epidemiological studies suggest that there is no consensus as to whether inhaled corticosteroids and bronchodilators increase or not the risk of congenital malformations in human. The ambiguous results of epidemiological studies may be influenced by the difficulty of distinguishing between two types of possible harmful effects on the embryo: i) Direct effects of the anti-asthma drug itself, and ii) indirect effects induced by changes in the maternal organism in response to asthma and its treatment.

The present study was motivated by three children with an orofacial cleft who were born in one family (Figure 1). The mother of these children suffered from bronchial asthma and was treated with inhaled Symbicort (a mixture of corticosteroid 
budesonide and bronchodilator formoterol) during all three pregnancies. We proposed the following hypothesis: Symbicort, formoterol, and budesonide have teratogenic potential and can induce orofacial cleft. We tested this hypothesis in experimental model. To eliminate the influence on embryonic development of changes in the maternal organism induced by asthma and its medication, we did not use a mammalian model (mouse, rat, rabbit) but instead used the chick embryo developing in the egg. This allowed us to monitor the drug-embryo interaction in isolation and to test experimentally the direct injurious effect of these anti-asthma drugs on developing embryonic organs in vivo.

\section{Materials and Methods}

Chick embryo - window technique. The effects of formoterol, budesonide and Symbicort were tested in developing chick embryos in vivo using the Chick Embryotoxicity Screening Test (CHEST) $(29,30)$. Cold fertile eggs (Cobb chicken breed) were placed horizontally in a forced-draft thermostatic oven and incubated at $37.5^{\circ} \mathrm{C}$ and $40-60 \%$ relative humidity and turned slightly every day until the day of drug administration. Immediately before the administration, the eggs were candled and windowed under aseptic conditions. A miniature disc grinder was used to make rectangular grooves in the shell. The incised shell rectangle and the outer membrane were removed by tweezers. The window method allows inspection of the embryos and their staging [according to Hamburger and Hamilton (31)] before administration, and the detection of spontaneously dead or malformed embryos to eliminate them from further experimental processing.

Drug administration and embryo harvesting. Original powder formulations of Symbicort Turbuhaler (AstraZeneca AB, Södertälje, Sweden), formoterol (formoterol Ratiopharm; Mercle $\mathrm{GmbH}$, Blaubeuren, Germany) and budesonide (Milfonid Breezhaler; Novartis, Prague, Czech Republic) were used. Symbicort was composed of budesonide and formoterol at a ratio of 33:1. Batches of the original powders were weighed and dissolved by decimal dilution in distilled water to achieve $3.0,0.3,0.03,0.003$ or $0.0003 \mu \mathrm{g}$ of active substance, respectively, per injection dose of $3 \mu$ l.

The drugs were administered on embryonic day 4 (ED) (Hamburger and Hamilton stage 21-24) and 5 (Hamburger and Hamilton stage 2527) of incubation. ED 4 and 5 were chosen to cover the critical developmental period of cleft beak origin in chick embryos (32-34).

Using a calibrated glass micropipette, each dose of the tested drug was injected intra-amniotically into 20 embryos at ED 4 or 5 for a total of 40 embryos per drug dose level, i.e. a total of 200 embryos per drug. The control group always comprised 20 embryos injected with distilled water on ED 4 or 5 (a total of 40 embryos).

After drug administration, the window in egg shell was closed with a glass slide, sealed with paraffin, and the eggs were further incubated without turning. The vitality of embryos was checked daily and dead embryos were set aside.

On ED 10, the surviving embryos were harvested, weighed, and examined for gross external malformations under a stereomicroscope. We searched for malformations of head (exencephaly, microcephaly), face (micropthalmia, buphthalmia, coloboma iridis, unilateral or bilateral cleft of beak, mandible hypoplasia), limbs and trunk (gastroschisis, spin defects, syndrome of caudal regression). In addition to the external examination, dissection of the heart was routinely performed for detection of ventricular septum defect and anomalies of great vessels. The number of living malformed embryos at day 10 or the number of embryos that died up to ED 10 was counted for each individual dose and day of injection.

For further evaluation of drug effects, the numbers of malformed and/ dead embryos for each individual dose on ED 4 and 5 were summed and averaged. Embryonic body weight was used to determine if there was any growth-retardation effect.

Determination of teratogenic/lethal dose. The teratogenic/lethal doses were determined on the basis of the dose-response curves. For each individual dose of Symbicort, formoterol or budesonide, the sum of dead plus malformed embryos, as evaluated on ED 10, was expressed as a percentage of all 40 embryos (100\%) exposed to the specific dose.

In previous studies, we repeatedly found an average of $20 \%$ of malformed plus dead control embryos that occur spontaneously or are induced by experimental intervention (e.g. 29, 30) (see also the present values for the control groups in Figure 2). Based on this mean value, the upper limit of the $95 \%$ confidence interval for the non-specific effect was calculated, according to Dixon and Massey (35), and Gartner and Altman (36), which corresponded to $30 \%$ of the exposed embryos. This implies an effect is significant at the 5\% level of statistical significance when administration of a dose induces embryonic malformation/death in more than $30 \%$ of the exposed embryos. Such doses were considered as teratogenic/lethal.

Separate determination of the lethal, teratogenic and growth retardation effects. In order to further analyse the harmful effect of a drug on a population of exposed embryos, we compared the separate dose-response curves of the teratogenic (number of malformed embryos) versus lethal (number of dead embryos) effects. To search for a growth-retardation effect, the body weight of the living malformed embryos was compared to those of the control group using Student's $t$-test for two independent means.

\section{Results}

Symbicort. The dose-response curve showed that the lowest doses of $0.0003 \mu \mathrm{g}$ and $0.003 \mu \mathrm{g}$ had no lethal or teratogenic effect. However, $70 \%$ of 40 injected embryos were damaged (dead or malformed) at a dose of $0.03 \mu \mathrm{g}$, while the remaining $30 \%$ were alive without malformation. A strong effect was detected at $0.3 \mu \mathrm{g}$ and $3.0 \mu \mathrm{g}$, at which $100 \%$ of the tested embryos were either dead or alive but malformed. In conclusion, the doses of $0.03 \mu \mathrm{g}, 0.3 \mu \mathrm{g}$ and $3.0 \mu \mathrm{g}$ of Symbicort exhibited a teratogenic/lethal effect (Figure 2A). We found gastroschisis in $71 \%$ and unilateral or bilateral cleft beak in 29\% (Figure 3B and D-F) of the living malformed embryos exposed to Symbicort at 0.03 and $0.3 \mu \mathrm{g}$. The dose of $3.0 \mu \mathrm{g}$ exhibited $100 \%$ lethality.

Formoterol. The dose-response curve showed the lowest doses $0.0003 \mu \mathrm{g}$ and $0.003 \mu \mathrm{g}$ had no lethal or teratogenic effect. At a dose of $0.03 \mu \mathrm{g}, 70 \%$ of injected embryos were alive without a malformation $30 \%$ of embryos were damaged (dead or 

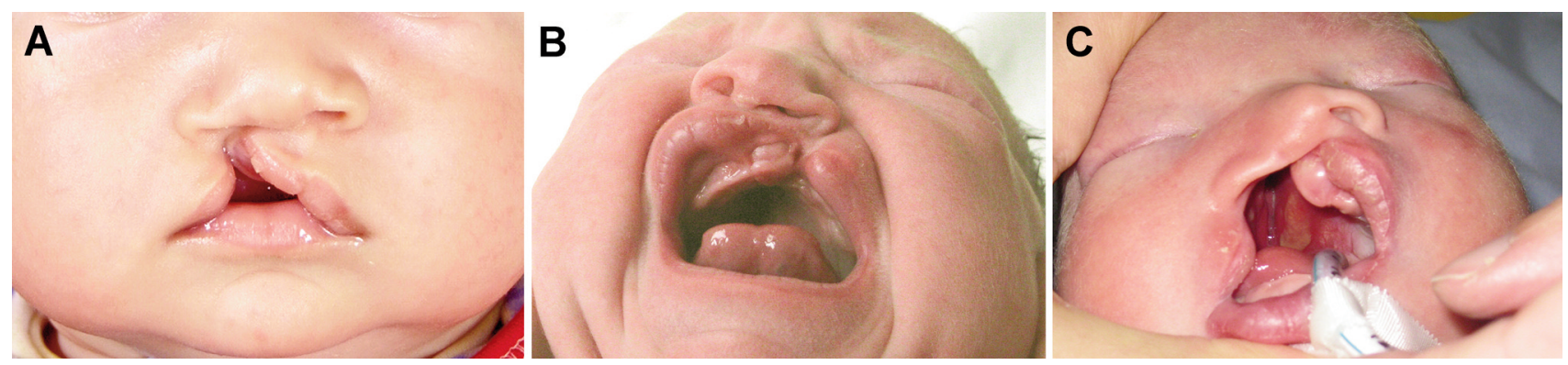

Figure 1. Three children with an orofacial cleft (CLP) born to a woman receiving treatment for bronchial asthma. A: Boy with unilateral CLP (rightsided) born in 2006. B: Girl with unilateral CLP (left-sided) born in 2009. C: Boy with unilateral CLP (right-sided) born in 2012. Family history was negative with respect to orofacial cleft. The mother of these children suffered from bronchial asthma and was treated with Symbicort in one inhaled dose $(200 \mu \mathrm{g})$ twice a day during all three pregnancies. (Photos from the photo archive of the Cleft Centre, Clinic of Plastic Surgery, Kralovske Vinohrady University Hospital, Prague, Czech Republic).

malformed). Such a weak effect was not statistically significant. A strong effect was detected at 0.3 and $3.0 \mu \mathrm{g}$, with $82 \%$ and $88 \%$ of the tested embryos, respectively, were either dead or alive but malformed. For formoterol, the teratogenic/lethal doses were $0.3 \mu \mathrm{g}$ and $3.0 \mu \mathrm{g}$ (Figure 2B). In the living malformed embryos at ED 10, gastroschisis and unilateral or bilateral cleft beak (Figure 3B and D-F) occurred in $5.6 \%$ and $51 \%$, respectively, and defects of heart ventricular septum were found in $43 \%$ after exposure to formoterol doses of 0.3 and $3.0 \mu \mathrm{g}$.

Budesonide. The dose-response curve showed that the lowest dose, $0.0003 \mu \mathrm{g}$, had no lethal or teratogenic effect. A weak embryotoxic effect was detected at $0.003 \mu \mathrm{g}$, at which $35 \%$ of injected embryos were damaged (dead or malformed), while the remaining $65 \%$ were alive without a malformation. However, all of the tested embryos were either dead or living malformed at a dose of $0.03 \mu \mathrm{g}$ and higher. For budesonide, the teratogenic/lethal doses were $0.003,0.03,0.3$ and $3.0 \mu \mathrm{g}$ (Figure 2C). In the living malformed embryos, gastroschis and cleft beak (Figure 3B and D-F) represented $75 \%$ and $25 \%$ of malformations, respectively at doses of $0.003-0.03 \mu \mathrm{g}$ of budesonide.

The testing of the study drugs showed budesonide to be the most deleterious in terms of its effects on the embryo: its harmful effects started at a dose 10 and 100 times lower than that of Symbicort and formoterol, respectively (Figure 2). Therefore, we subjected budesonide to a more detailed analysis focusing on its lethal, teratogenic and growthretardation effects.

Separate dose-response relationships after exposure to budesonide. The separate dose-response curve considering only dead embryos (i.e. an embryo-lethal effect) rose gradually from $20 \%$ after exposure to $0.0003 \mu \mathrm{g}$ of budesonide to $100 \%$ when embryos were exposed to $3.0 \mu \mathrm{g}$ of budesonide (Figure 4).
The separate dose-response curve considering only living malformed embryos (i.e. a teratogenic effect) had a completely different shape. None of the living embryos was malformed after administration at the lowest dose $(0.0003 \mu \mathrm{g})$ of budesonide. When the dose increased from 0.003 to $0.03 \mu \mathrm{g}$, the number of malformed living embryos also increased in a similar pattern. The percentage of the living malformed embryos reached a maximum at $0.03 \mu \mathrm{g}$, when all the surviving embryos were malformed $(40 \%)$, while all the remaining embryos $(60 \%)$ died; this implies there were no surviving embryos without a malformation (Figure 4). With increasing budesonide dose, the percentage of living malformed embryos decreased because the highest dose $3.0 \mu \mathrm{g}$ of budesonide caused death of all tested embryos (Figure 4).

Growth retardation after exposure to budesonide. Growth retardation was measured as a reduction of body weight in comparison to the control group. The body weight was measured in all living embryos - i.e. in living embryos with and without a malformation, on ED 10. The mean body weight of the control embryos was $2,561 \pm 865.6 \mathrm{mg}$. In the specimens exposed to $0.0003 \mu \mathrm{g}$ of budesonide, the mean body weight of $2,477 \pm 851.6 \mathrm{mg}$ was not significantly different from that of the control group. However, the mean body weight progressively decreased with increasing dose of budesonide. After budesonide injections of $0.003,0.03$ and 0.3 $\mu \mathrm{g}$, the mean body weight of the living embryos significantly decreased to $2,367 \pm 708.9 \mathrm{mg}(p<0.05), 1,803 \pm 413.9 \mathrm{mg}$ $(p<0.01)$ and $1,256 \pm 200.6 \mathrm{mg}(p<0.01)$, respectively. The body weight could not be evaluated after the $100 \%$ lethal dose $(3.0 \mu \mathrm{g})$, at which no specimens survived.

\section{Discussion}

Among the drugs compared according to their lowest embryotoxic dose inducing a teratogenic/lethal effect, 

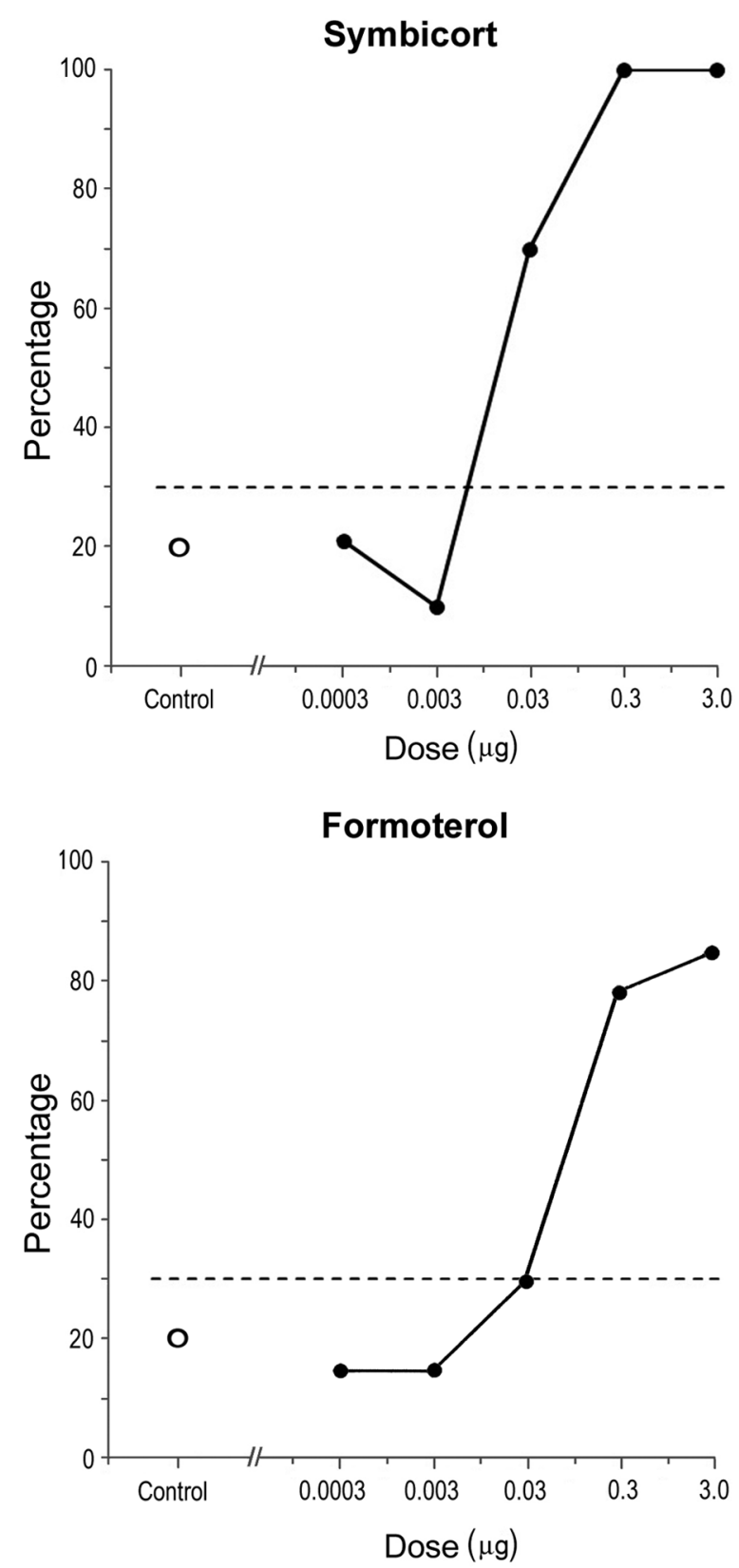

budesonide was the most harmful while formoterol was the least deleterious (with lowest teratogenic/lethal dose $0.003 \mu \mathrm{g}$ and $0.3 \mu \mathrm{g}$, respectively). Symbicort, a mixture of budesonide and formoterol, had an embryo damaging effect at the lowest dose of $0.03 \mu \mathrm{g}$.

The tested anti-asthma drugs exhibited lethal, teratogenic and growth-retardation effects.

Teratogenic effect of anti-asthmatics. In general, the ability of corticoids to induce orofacial clefts in experimental mammals

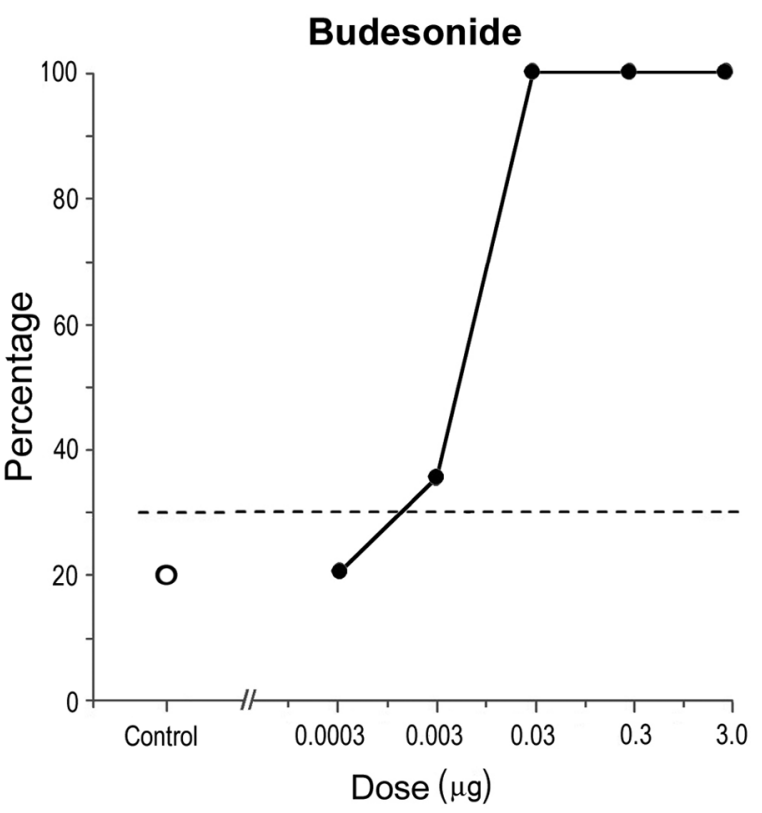

Figure 2. Effect of antiasthmatics in chick embryos in vivo. The figure shows the percentage of malformed plus dead embryos (teratogenic/lethal effect) after a single intra-amniotic injection of increasing doses of Symbicort (A), formoterol (B), and budesonide (C). The dashed horizontal line indicates the $95 \%$ confidence interval level, which corresponds to the maximum background frequency of malformed and dead control embryos that occur spontaneously or are induced by experimental intervention. All values that exceed this level are considered as having a teratogenic/lethal specific effect. Circles indicate the value of the study control group.

has been known since the 1950s (37-39). Regarding budesonide, Kihlström and Lundberg carried out an experimental teratogenic study in which the drug was administered subcutaneously to pregnant rabbits during the organogenetic period. At the highest dose, all females miscarried; the offspring of the females which received lower doses of budesonide showed intrauterine growth retardation and skeletal anomalies (40). In the present experimental study, administration of effective doses of all three anti-asthma drugs resulted in developmental malformations: gastroschisis and 

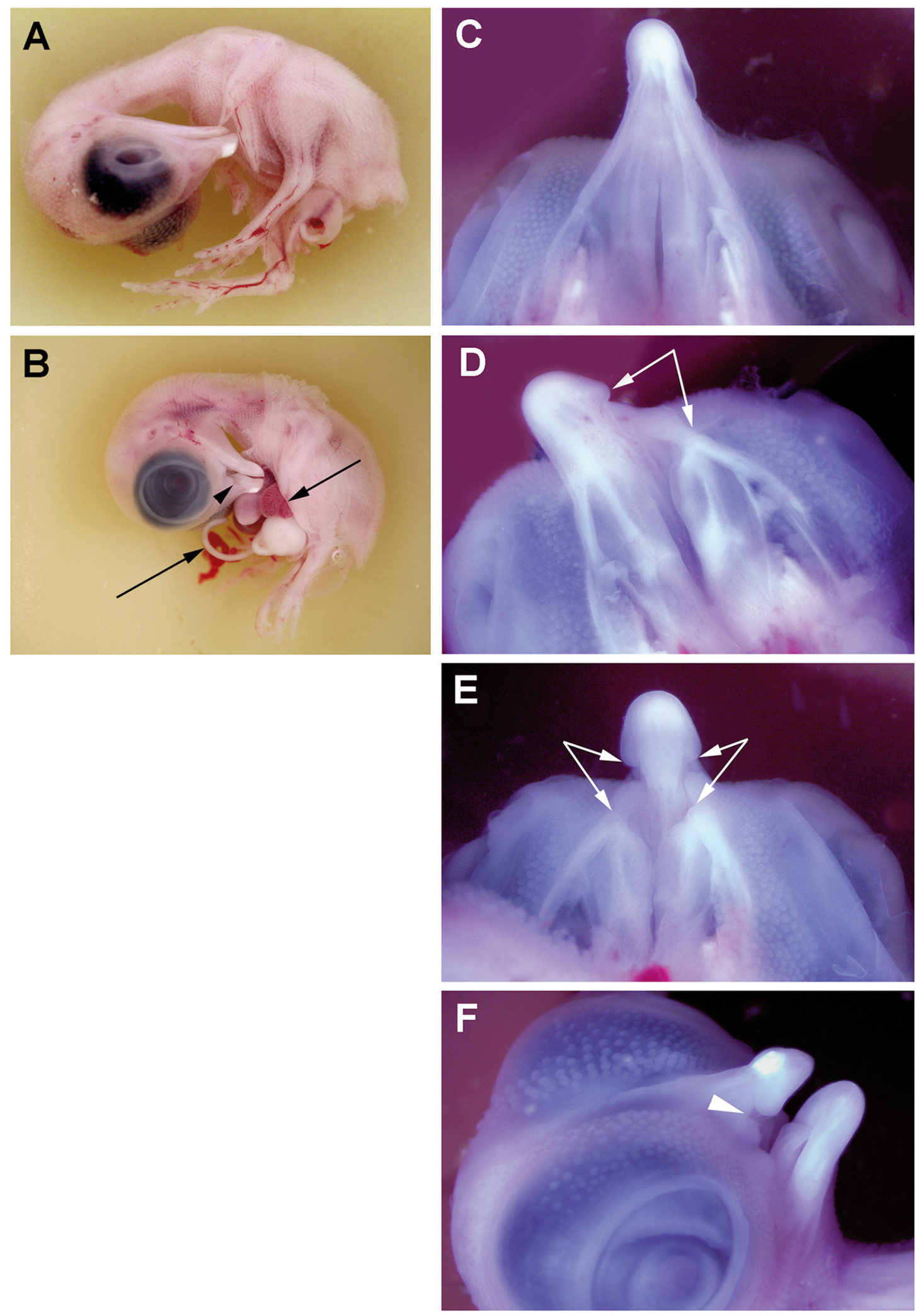

Figure 3. Malformations in chick embryos exposed to budesonide. Control $(A, C)$ and malformed $(B, D, E, F)$ chick embryos after a single injection of $0.3 \mu \mathrm{g}$ of budesonide on embryonic day 4 . Arrowhead points to a cleft beak $(B, F)$. Arrows indicate the limits of gastroschisis $(B)$ and unilateral $(D)$ or bilateral (E) cleft beak. The anomalies induced by budesonide were not morphologically different from those induced by Symbicort or formoterol. 


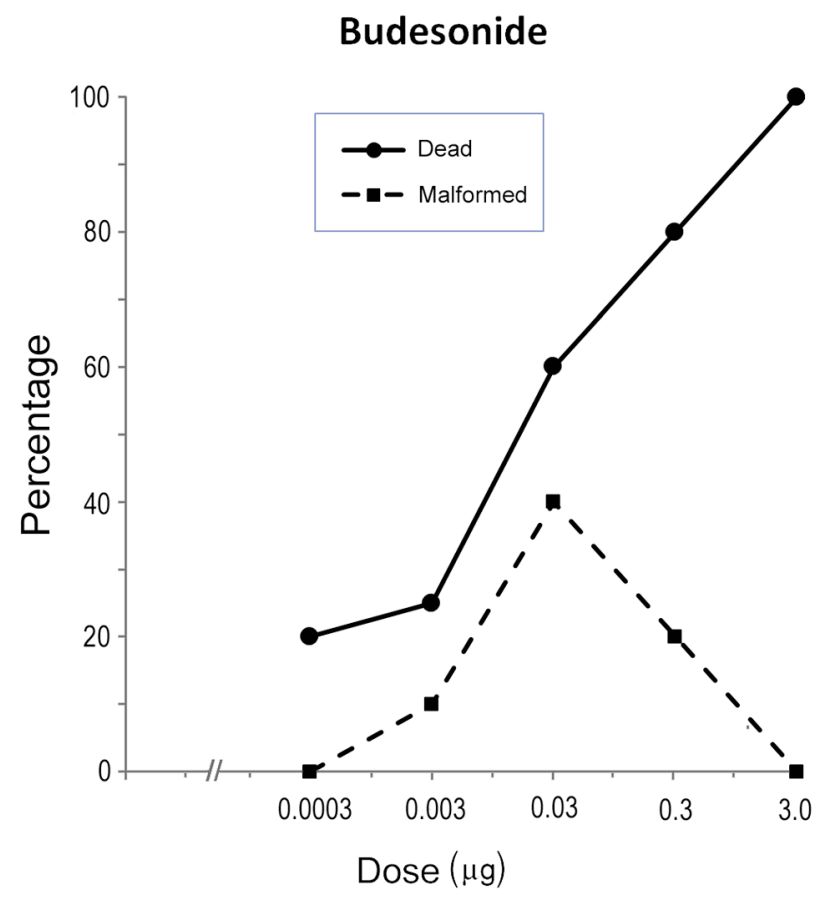

Figure 4. Teratogenic and lethal effects of budesonide in chick embryos in vivo. The figure shows the percentage of living malformed (dashed line) and dead (full line) chick embryos after a single intra-amniotic injection of one of five increasing doses of budesonide. As a consequence of the increase in the number of dead embryos at the highest doses 0.3 $\mu \mathrm{g}$ or $3.0 \mu \mathrm{g}$, the number of living malformed embryos (dashed line) decreases. The graph shows that the evaluation of teratogenicity itself is not sufficient to assess the most injurious effect of a drug.

cleft of beak. Moreover, formoterol exhibited an injurious effect on the developing heart. All these kinds of malformations have also been reported in newborns whose mothers have been treated for asthma during pregnancy. A combined medication of maternal asthma during pregnancy using inhaled corticoids and bronchodilators has been correlated with the presence of omphalocele (quantitatively a milder defect than gastroschisis), and anorectal and esophageal atresia in babies $(41,42)$. Regarding bronchodilators, a significant association has been reported between maternal medication and risk of gastroschisis, orofacial clefts and heart defects in offspring $(21,25,27,28)$. Administration of corticoids for asthma treatment during pregnancy has been correlated with orofacial clefts (10) and with increased risk of less severe cardiovascular defects in children $(18,43)$. However, the number of living malformed newborns is not a sufficient parameter to measure the impact of an injurious factor (drug or a harmful substance in environment) on pregnancy outcome. The number of congenital malformations only reflects one component of the embryo-damaging effect of a factor, which can be revealed by teratological epidemiological studies. Apart from teratogenicity, there is a more severe or less severe component of embryotoxicity with an impact on pregnancy outcome, corresponding to lethality or growth retardation (low body weight), respectively $(44,45)$.

Growth-retardation effect of budesonide. The mean body weight of the surviving chick embryos was progressively and significantly reduced by an increasing dose of budesonide, until its lethal dose. A significant decrease in the mean body weight of living embryos has also been documented after the injection of budesonide to pregnant rabbit females (40). In humans, intrauterine growth retardation/restriction is characterized by an estimation of fetal weight lower than the 10th percentile for the appropriate gestational age, and may be caused by fetal, maternal, and environmental issues (46). Similarly, a birth weight below the 10th percentile for the gestational age is most commonly used to define newborns that are small for their gestational age. Increased risk of a low birth weight has been reported in newborns of mothers treated by corticosteroids (1, $10,19,20)$. Yland et al. found an association between asthma severity and small gestational age (47).

Lethal effect of budesonide. In the present experimental study, the number of both living malformed and dead embryos increased with increasing dose at doses up to 0.03 $\mu \mathrm{g}$ (Figure 4). As the dose further increased, the death rate continued to increase. However, the number of surviving malformed embryos in fact declined until reaching zero at the highest dose (Figure 4). A similar phenomenon has also been observed the studies on many other substances $(30,48$, 49) and suggests the evaluation of teratogenicity alone is not sufficient to assess the most injurious effect of embryodamaging factors. For example, teratogenicity studies only examining higher doses of a substance might lead to the erroneous conclusion that the substance is safe since it has no teratogenic effect on the embryo. A lethal effect was also observed in the rabbit, when all females miscarried at the highest dose of budesonide (40). According to the authors, a direct lethal effect of budesonide cannot be excluded, but severe injury of the rabbit females and their reaction to the high dose of budesonide might also have had a negative impact on the pregnancy outcome (40). Monitoring of spontaneous abortions in humans encounters difficulties mainly in the detection of early abortions

A chick embryo in vivo model - its benefits and limits. In the present study, an in vivo model on a chick embryo [the CHEST method $(29,30)]$ was employed. In accordance with Food and Drug Administration guidance (50), the method used can detect the three major manifestations of developmental toxicity, namely mortality, dysmorphogenesis (structural abnormalities) and alterations of growth (body weight). This method also reveals dose-response relationships (e.g. Figure 2). However, 
the chick embryo model cannot provide information on placental transport of the tested substance.

Due to the window technique, the CHEST method allows i) the selection of the developmental stage and the control of the condition of the embryos entering the experiment; ii) injection of the test substance in the immediate vicinity of the embryos; and iii) monitoring of the embryos during the subsequent incubation until their harvesting. A limitation may be that implementation of this method requires relatively longer training to achieve practical skills and experience for the entire application team.

Because the test substance does not reach the embryo via a maternal organism (as in mammalian testing), the CHEST method allows testing of the direct embrotoxicity of the test substance. Its advantage is that the result is not skewed by the effect of test agent metabolites like those which are produced in mammals. On the other hand, compared to mammals, the chick embryo in vivo model cannot provide information on the complex effect of the tested substance, including its species-specific metabolites produced by the maternal organism.

Regarding the above limits, the CHEST method (51-53) is an alternative means of testing developmental toxicity in a chick embryo in vivo. The purpose of this method is not to replace official routine procedures but to contribute to the development of new predictive systems based on the latest teratological findings (53).

Anti-asthmatics and critical period of development of orofacial clefts. Asthma is a chronic inflammatory disease affecting airways resulting in obstruction of airflow and bronchial hyper-responsiveness (54). Budesonide belongs to the corticosteroids used as the most effective anti-asthmatics. Their effect is mainly mediated by suppression of multiple inflammatory genes via specific glucocorticosteroid receptors (54). The glucosteroid receptors are also implicated in the pathogenesis of cleft beak in the chick embryo (32, 33) and cleft palate in the mouse (55).

Formoterol belongs to the group of bronchodilators being used in asthma medication as selective $\beta 2$-adrenoreceptor agonists. The $\beta 2$-adrenoreceptors are widely distributed in the lungs, in airway smooth muscle cells, as well as in epithelial and endothelial cells. The use of $\beta 2$-adrenoreceptor agonists leads to bronchodilation, due to airway smooth muscle relaxation, via canonical signaling mediated by cAMP (56-58).

Intra-pulmonary inhalation of anti-asthmatics in human volunteers was shown to lead to immediate absorption in lung alveoli; the maximum plasma level of antiasthmatics (budesonide/formoterol) is achieved within 30 minutes and the plasma concentration gradually decreases to nearly zero within 8 hours $(59,60)$. It is expected that these agents can therefore reach the embryo in a matter of minutes. Orofacial clefts are one of the most common developmental defects in children born to women suffering from bronchial asthma. These defects, as well as other major congenital malformations, arise during a limited phase (critical period) of embryonic development, between days 30-60 after conception in humans $(45,61)$.

Epidemiological studies suggest the administration of inhaled corticoids and bronchodilators during pregnancy increases the risk of major developmental malformations (17, $21,25,26)$. Taking the critical period of their origin into account (see above) may offer the following option to reduce the risk of development of orofacial clefts and other major congenital malformations in children: For example, in women with asthma exhibiting seasonal variation, conception may be planned so that the critical period for risk of major congenital malformations does not overlap with the period of asthma relapse. The critical period should also not overlap with seasons of respiratory infections or of hot weather, when the incidence of orofacial clefts in the Czech population was found to be increased (61). In women with continuous anti-asthma medication, time-limited reduction of therapeutic doses may be considered during the critical period of development of major malformations.

Our results seek to contribute to efforts to minimize the adverse effects of asthma treatment on offspring in terms of the development of major congenital malformations.

\section{Conclusion}

Developmental anomalies and embryonic death (teratogenic/lethal effect) were found in chick embryos developing in the egg after a single intra-amniotic injection of budesonide or formoterol, and their combination in the proprietary drug Symbicort. Budesonide was the most harmful and its teratogenic/lethal effect was apparent at already at a dose as low as $0.003 \mu \mathrm{g}$. Formoterol was the least deleterious with effects not becoming apparent until a higher dose $(0.3$ $\mu \mathrm{g})$. The embryo damaging -teratogenic/lethal effects of Symbicort (mixture of budesonide and formoterol) ware between these doses. Orofacial clefts and gastroschisis were found in the embryos exposed for all three drugs. Heart septum defects were found, in addition, after exposure to formoterol. These congenital malformations have been reported in offspring of women medicated for bronchial asthma during pregnancy. The present experimental results support the clinical/epidemiological studies that warn of the risk of developmental defects in the offspring of women treated with anti-asthmatics during pregnancy.

\section{Conflicts of Interest}

The Authors declare that they have no known competing financial interests or personal relationships that could have appeared to influence the work reported in this article. 


\section{Authors' Contributions}

The Authors declare that all data were generated in-house and no paper mill was used. MP, LH and RP conceived and designed research. MP and RP conducted experiments. MP, LH, and RP analysed data. MP, AS, LH and RP wrote the article. All Authors read and approved the final version of the article.

\section{Acknowledgements}

The Authors are grateful to Petra Herlova for her technical assistance with the CHEST method. This study was supported by the Charles University in Prague, Czech Republic (Research Program Progress - Q16 and Research Program Progress - Q28) and by the Grant Agency of the Czech Republic (Grant No.14-37368G).

\section{References}

1 Schatz M: The efficacy and safety of asthma medications during pregnancy. Semin Perinatol 25(3): 145-152, 2001. PMID: 11453610. DOI: $10.1053 /$ sper.2001.24569

2 Sawicki E, Stewart K, Wong S, Paul E, Leung L and George J: Management of asthma by pregnant women attending an Australian maternity hospital. Aust N Z J Obstet Gynaecol 52(2): 183-138, 2012. PMID: 22141407. DOI: 10.1111/j.1479828X.2011.01385.x

3 Jølving LR, Nielsen J, Kesmodel US, Nielsen RG, Beck-Nielsen SS and Nørgård BM: Prevalence of maternal chronic diseases during pregnancy - a nationwide population based study from 1989 to 2013. Acta Obstet Gynecol Scand 95(11): 1295-1304, 2016. PMID: 27560844. DOI: $10.1111 /$ aogs.13007

4 Clifton VL: Managing asthma in pregnancy: effects on future child health. Lancet Respir Med 7(6): 485-486, 2019. PMID: 31122732. DOI: 10.1016/S2213-2600(19)30149-3

5 Taytard J, Lacin F, Nguyen TLT, Boizeau P, Alberti C and Beydon $\mathrm{N}$ : Children with uncontrolled asthma and significant reversibility might show hypoxaemia. Eur J Pediatr 179(6): 999-1005, 2020. PMID: 32020332. DOI: 10.1007/s00431-020-03600-z

6 Rance $\mathrm{K}$ and O'Laughlen MC: Managing asthma during pregnancy. J Am Assoc Nurse Pract 25(10): 513-521, 2013. PMID: 24170482. DOI: 10.1002/2327-6924.12052

7 Tan KS and Thomson NC: Asthma in pregnancy. Am J Med 109(9): 727-733, 2000. PMID: 11137489. DOI: 10.1016/s00029343(00)00615-x

8 Dombrowski MP and Schatz M: Asthma in pregnancy. Clin Obstet Gynecol 53(2): 301-310, 2010. PMID: 20436305. DOI: 10.1097/GRF.0b013e3181de8906

9 Murphy VE, Wang G, Namazy JA, Powell H, Gibson PG, Chambers $\mathrm{C}$ and Schatz $\mathrm{M}$ : The risk of congenital malformations, perinatal mortality and neonatal hospitalisation among pregnant women with asthma: a systematic review and meta-analysis. BJOG 120(7): 812-822, 2013. PMID: 23530780. DOI: $10.1111 / 1471-0528.12224$

10 Murphy VE and Schatz M: Asthma in pregnancy: a hit for two. Eur Respir Rev 23(131): 64-68, 2014. PMID: 24591663. DOI: $10.1183 / 09059180.00008313$

11 Bonham CA, Patterson KC and Strek ME: Asthma Outcomes and Management During Pregnancy. Chest 153(2): 515-527, 2018. PMID: 28867295. DOI: 10.1016/j.chest.2017.08.029
12 Lasserson TJ, Ferrara G and Casali L: Combination fluticasone and salmeterol versus fixed dose combination budesonide and formoterol for chronic asthma in adults and children. Cochrane Database Syst Rev (12): CD004106, 2011. PMID: 22161385. DOI: 10.1002/14651858.CD004106.pub4

13 Kew KM, Karner C, Mindus SM and Ferrara G: Combination formoterol and budesonide as maintenance and reliever therapy versus combination inhaler maintenance for chronic asthma in adults and children. Cochrane Database Syst Rev 12: CD009019, 2013. PMID: 24343671. DOI: 10.1002/14651858.CD009019.pub2

14 Murphy VE: Managing asthma in pregnancy. Breathe (Sheff) 11(4): 258-267, 2015. PMID: 27066119. DOI: 10.1183/20734735.007915

15 Namazy J and Schatz M: The Treatment of Allergic Respiratory Disease During Pregnancy. J Investig Allergol Clin Immunol 26(1): 1-7; quiz 2p following 7, 2016. PMID: 27012010.

16 National Heart, Lung, and Blood Institute. and National Asthma Education and Prevention Program Asthma and Pregnancy Working Group: NAEPP expert panel report. Managing asthma during pregnancy: recommendations for pharmacologic treatment-2004 update. J Allergy Clin Immunol 115(1): 34-46, 2005. PMID: 15637545. DOI: 10.1016/j.jaci.2004.10.023

17 Carmichael SL, Shaw GM, Ma C, Werler MM, Rasmussen SA, Lammer EJ and National Birth Defects Prevention Study: Maternal corticosteroid use and orofacial clefts. Am J Obstet Gynecol 197(6): 585.e1-7; discussion 683-684, e1-7, 2007. PMID: 18060943. DOI: 10.1016/j.ajog.2007.05.046

18 Blais L and Forget A: Asthma exacerbations during the first trimester of pregnancy and the risk of congenital malformations among asthmatic women. J Allergy Clin Immunol 121(6): 13791384, 1384.e1, 2008. PMID: 18410961. DOI: 10.1016/j.jaci.2008. 02.038

19 Rocklin RE: Asthma, asthma medications and their effects on maternal/fetal outcomes during pregnancy. Reprod Toxicol 32(2): 189-197, 2011. PMID: 21684328. DOI: 10.1016/j.reprotox.2011. 05.023

20 Gur C, Diav-Citrin O, Shechtman S, Arnon J and Ornoy A: Pregnancy outcome after first trimester exposure to corticosteroids: a prospective controlled study. Reprod Toxicol 18(1): 93-101, 2004. PMID: 15013068. DOI: 10.1016/j.reprotox.2003.10.007

21 Lin S, Munsie JP, Herdt-Losavio ML, Bell E, Druschel C, Romitti PA, Olney R and National Birth Defects Prevention Study.: Maternal asthma medication use and the risk of gastroschisis. Am J Epidemiol 168(1): 73-79, 2008. PMID: 18436535. DOI: $10.1093 / \mathrm{aje} / \mathrm{kwn} 098$

22 Hviid A and Mølgaard-Nielsen D: Corticosteroid use during pregnancy and risk of orofacial clefts. CMAJ 183(7): 796-804, 2011. PMID: 21482652. DOI: 10.1503/cmaj.101063

23 Bay Bjørn AM, Ehrenstein V, Hundborg HH, Nohr EA, Sørensen HT and Nørgaard M: Use of corticosteroids in early pregnancy is not associated with risk of oral clefts and other congenital malformations in offspring. Am J Ther 21(2): 73-80, 2014. PMID: 23011170. DOI: 10.1097/MJT.0b013e3182491e02

24 Skuladottir H, Wilcox AJ, Ma C, Lammer EJ, Rasmussen SA, Werler MM, Shaw GM and Carmichael SL: Corticosteroid use and risk of orofacial clefts. Birth Defects Res A Clin Mol Teratol 100(6): 499-506, 2014. PMID: 24777675. DOI: 10.1002/bdra.23248

25 Garne E, Hansen AV, Morris J, Zaupper L, Addor MC, Barisic I, Gatt M, Lelong N, Klungsøyr K, O’Mahony M, Nelen V, Neville AJ, Pierini A, Tucker D, de Walle H, Wiesel A, Loane M and Dolk $\mathrm{H}$ : Use of asthma medication during pregnancy and risk of 
specific congenital anomalies: A European case-malformed control study. J Allergy Clin Immunol 136(6): 1496-1502.e7, 2015. PMID: 26220526. DOI: 10.1016/j.jaci.2015.05.043

26 Lin S, Herdt-Losavio M, Gensburg L, Marshall E and Druschel C: Maternal asthma, asthma medication use, and the risk of congenital heart defects. Birth Defects Res A Clin Mol Teratol 85(2): 161168, 2009. PMID: 19067406. DOI: 10.1002/bdra.20523

27 Munsie JW, Lin S, Browne ML, Campbell KA, Caton AR, Bell EM, Rasmussen SA, Romitti PA, Druschel CM and National Birth Defects Prevention Study: Maternal bronchodilator use and the risk of orofacial clefts. Hum Reprod 26(11): 3147-3154, 2011. PMID: 21926056. DOI: 10.1093/humrep/der315

28 Eltonsy S, Kettani FZ and Blais L: Beta2-agonists use during pregnancy and perinatal outcomes: a systematic review. Respir Med 108(1): 9-33, 2014. PMID: 24360293. DOI: 10.1016/ j.rmed.2013.07.009

29 Jelinek R, Peterka M and Rychter Z: Chick embryotoxicity screening test-130 substances tested. Indian J Exp Biol 23(10): 588-595, 1985. PMID: 3833676.

30 Peterka M, Jelínek R and Pavlík A: Embryotoxicity of 25 psychotropic drugs: a study using CHEST. Reprod Toxicol 6(4): 367-374, 1992. PMID: 1521011. DOI: 10.1016/0890-6238(92) 90201-4

31 Hamburger V and Hamilton HL: A series of normal stages in the development of the chick embryo. J Morphol 88(1): 49-92, 1951. PMID: 24539719.

32 Peterka M and Jelinek R: Origin of hydrocortisone induced orofacial clefts in the chick embryo. Cleft Palate J 20(1): 35-46, 1983. PMID: 6572574.

33 Jelínek R, Pavlík A and Peterka M: Glucocorticoid receptormediated teratogenesis in the chick embryo. Teratog Carcinog Mutagen 3(1): 1-7, 1983. PMID: 6188228. DOI: 10.1002/15206866(1990)3:1<1::aid-tcm1770030102>3.0.co;2-q

34 Peterka M, Peterková R and Likovský Z: Cleft beak induced by hydrocortisone in the chick is prevented by increased cell division after experimental reduction of amniotic fluid. Anat Embryol (Berl) 195(4): 387-391, 1997. PMID: 9108205. DOI: $10.1007 /$ s004290050059

35 Dixon WJ and Massey FJ: Introduction to statistical analysis. McGraw-Hill, New York, pp. 77-79, 1969.

36 Gardner MJ and Altman DG: Confidence intervals rather than $\mathrm{P}$ values: estimation rather than hypothesis testing. Br Med J (Clin Res Ed) 292(6522): 746-750, 1986. PMID: 3082422. DOI: $10.1136 / \mathrm{bmj} .292 .6522 .746$

37 Baxter $\mathrm{H}$ and Fraser FC: The production of congenital defects in the offspring of female mice treated with cortisone. A preliminary report. McGill Med J 19(4): 245-249, 1950. PMID: 14795899

38 Fraser FC and Fainstat TD: Production of congenital defects in the off-spring of pregnant mice treated with cortisone; progress report. Pediatrics 8(4): 527-533, 1951. PMID: 14882906.

39 Ziejewski MK, Solomon HM, Stanislaus D, Clark RL, White TE and Apostoli AR: The potential role for corticosterone in the induction of cleft palate in mice after treatment with a selective NK-1 receptor antagonist, casopitant (GW679769B). Birth Defects Res B Dev Reprod Toxicol 95(1): 54-62, 2012. PMID: 22127931. DOI: 10.1002/bdrb.20341

40 Kihlström I and Lundberg C: Teratogenicity study of the new glucocorticosteroid budesonide in rabbits. Arzneimittelforschung 37(1): 43-46, 1987. PMID: 3566856.
41 Källén B, Rydhstroem $\mathrm{H}$ and Aberg A: Congenital malformations after the use of inhaled budesonide in early pregnancy. Obstet Gynecol 93(3): 392-395, 1999. PMID: 10074986.

42 Källén BA and Otterblad Olausson P: Maternal drug use in early pregnancy and infant cardiovascular defect. Reprod Toxicol 17(3): 255-261, 2003. PMID: 12759093. DOI: 10.1016/s08906238(03)00012-1

43 Gluck PA and Gluck JC: A review of pregnancy outcomes after exposure to orally inhaled or intranasal budesonide. Curr Med Res Opin 21(7): 1075-1084, 2005. PMID: 16004676. DOI: 10.1185/030079905X50570

44 Wilson JG: Current status of teratology. In: Handbook of Teratology. Wilson JG and Fraser FC (eds.). Plenum Press, New York, pp. 47-74, 1977.

45 Peterka M, Likovsky Z and Peterkova R: Environmental risk and sex ratio in newborns. In: Congenital Diseases and the Environment. Nicolopolou-Stamati P, Hens L and Howard CV (eds.). Springer, pp. 295-319, 2007.

46 Hendrix N and Berghella V: Non-placental causes of intrauterine growth restriction. Semin Perinatol 32(3): 161-165, 2008. PMID: 18482615. DOI: 10.1053/j.semperi.2008.02.004

47 Yland JJ, Bateman BT, Huybrechts KF, Brill G, Schatz MX, Wurst KE and Hernández-Díaz S: Perinatal Outcomes Associated with Maternal Asthma and Its Severity and Control During Pregnancy. J Allergy Clin Immunol Pract 8(6): 1928-1937.e3, 2020. PMID: 31981730. DOI: 10.1016/j.jaip.2020.01.016

48 Peterka M, Havránek $\mathrm{T}$ and Jelínek R: Dose-response relationships in chick embryos exposed to embryotoxic agents. Folia Morphol (Praha) 34(1): 69-77, 1986. PMID: 3699640.

49 Peterka M, Mandys V, Viale M, Cafaggi S, Peterková R and Esposito M: Embryotoxicity of cisplatin and a cisplatin-procaine complex (DPR) studied in chick embryo. Neoplasma 49(6): 394400, 2002. PMID: 12584587.

50 FDA Guidance: Guidance for Industry Reproductive and Developmental Toxicities - Integrating Study Results to Assess Concerns, 2011. Available at: https://www.fda.gov/media/ 72231/download

51 Jelinek R: The Chick Embryotoxicity Screning Test (CHEST). In: Methods in Prenatal Toxicology. Neubert D, Merker HJ and Kwasigroch TE (Eds). Georg Thieme Publishers, Stuttgard, pp. 381-386, 1977.

52 Jelinek R and Peterka M: Morphogenetic systems and in vitro techniques in teratology. In: Culture Technique. Applicability for Studies on Prenatal Differentiation and Toxicity. Neubert D. and Merker H.J. (Eds). Walter Gruyter, Berlin, pp. 553-557, 1981.

53 Jelínek $\mathrm{R}$ and Marhan $\mathrm{O}$ : Validation of the Chick Embryotoxicity Screening Test (CHEST). A comparative study. Funct Dev Morphol 4(4): 317-323, 1994. PMID: 7612953.

54 Barnes PJ: Glucocorticosteroids. In: Handbook of Experimental Pharmacology. Volume 237. Pharmacology and Therapeutics of Asthma and COPD. Barrett JE, Page CP and Barnes PJ (eds). Springer, pp. 93-116, 2017. DOI: 10.1007/ 978-3-319-52175-6

55 Jelínek R and Dostál M: Morphogenesis of cleft palate induced by exogenous factors VII. Mitotic activity during formation of the mouse secondary palate. Folia Morphol (Praha) 22(1): 94101, 1974. PMID: 4476676.

56 Selroos O: Formoterol used as needed-clinical effectiveness. Respir Med 95(Suppl B): S17-20, 2001. PMID: 11534891. DOI: 10.1053/rmed.2001.1141 
57 Johnson M: Molecular mechanisms of beta(2)-adrenergic receptor function, response, and regulation. J Allergy Clin Immunol 117(1): 18-24; quiz 25, 2006. PMID: 16387578. DOI: 10.1016/j.jaci.2005.11.012

58 Dickey BF, Walker JK, Hanania NA and Bond RA: betaAdrenoceptor inverse agonists in asthma. Curr Opin Pharmacol 10(3): 254-259, 2010. PMID: 20399707. DOI: 10.1016/j.coph.2010. 03.002

59 Lähelmä S, Kirjavainen M, Kela M, Herttuainen J, Vahteristo M, Silvasti M and Ranki-Pesonen M: Equivalent lung deposition of budesonide in vivo: a comparison of dry powder inhalers using a pharmacokinetic method. Br J Clin Pharmacol 59(2): 167-173, 2005. PMID: 15676038. DOI: 10.1111/j.1365-2125.2004. 02238.x
60 Lähelmä S, Sairanen U, Haikarainen J, Korhonen J, Vahteristo $\mathrm{M}$, Fuhr $\mathrm{R}$ and Kirjavainen $\mathrm{M}$ : Equivalent lung dose and systemic exposure of budesonide/formoterol combination via easyhaler and turbuhaler. J Aerosol Med Pulm Drug Deliv 28(6): 462-473, 2015. PMID: 25757188. DOI: 10.1089/jamp.2014.1195

61 Peterka M, Likovsky Z, Panczak A and Peterkova R: Long-term significant seasonal differences in the numbers of new-borns with an orofacial cleft in the Czech Republic - a retrospective study. BMC Pregnancy Childbirth 18(1): 348, 2018. PMID: 30153794. DOI: 10.1186/s12884-018-1981-0

Received January 7, 2021

Revised February 3, 2021

Accepted February 5, 2021 